The $5^{\text {th }}$ International Conference on Family Business and Entrepreneurship

\title{
NEW NORMAL EDUCATIONAL LEADERSHIP AND MANAGEMENT OF GEOGRAPHICALLY CHALLENGED SCHOOL ADMINISTRATORS IN THE DIVISION OF CAPIZ
}

\author{
Ferry Rafunzel B. Manuba ${ }^{1}$, Ryan B. Estillomo ${ }^{2}$ \\ ${ }^{1,2}$ Faculty of Business, Colegio de la Purisima Concepcion, Corresponding author: sgs@purisima.edu.ph
}

\begin{abstract}
The pandemic has ramshackle the already technologically debilitated condition of education extenuating the need for forces, knowledge and talents of teachers and parents toward achieving better education. With this, the study determined the educational leadership and management challenges of school administrators in the Division of Capiz which may serve as basis in creating primers for supplementary material of the Learning Continuity Plan. Specifically, it covered the changes, challenges, managerial skills and leadership styles of school administrators. In-depth unstructured Interviews using openended questions were used to gather the data from six (6) selected school administrators in the Division of Capiz. The data gathered were analyzed through the qualitative data analysis procedures presented by Powell and Renner (2003). The themes identified were based on the changes encountered by the school administrators in the new normal setting. These were on organizational management strategies, personnel monitoring, instructional delivery system, and health management protocols. The identified themes based on the challenges experienced by school administrators as to the implementation of the new normal setting of education were poor internet connection, transportation fare hike, threats on health and safety, parents' involvement, scarcity of school resources and adjustments.
\end{abstract}

Keywords: Educational, Leadership, Management, Geographically, Challenged

\section{Introduction}

The most powerful weapon for changing the world is education. It eliminates inequality, reduces poverty, creates a sustainable planet, prevents needless deaths and illness, and fosters peace (Duncan, 2011). Stated in UNESCO's Millennium Development Goal of Basic Education for All (EFA), one key solution to end poverty and inequalities is to provide people with appropriate education. However not everyone is given the chance to enjoy the privilege. The disparaties are even deeper considering the urban and the rural areas of the developing countries.

Education for rural people is crucial to achieving both the Education for All (EFA) goals and the Millennium Development Goals (MDGs) aimed at eradicating extreme poverty and hunger, ensuring universal primary education, promoting gender equity and ensuring environmental sustainability. In 1996, the World Food Summit in Rome stressed increased access to education for the poor and members of disadvantaged groups, including rural people, as a key to achieving poverty eradication, food security, durable peace and sustainable development.

The report of Commonwealth Schools Commission Australia in 1975, exposed that there was educational disadvantage at a secondary level in rural areas from factors such as isolation, non-access to cultural 
facilities, the range and level of local employment, and the educational levels and incomes of families. Specifically, rural schools have suffered from high teacher turnover, a lack of specialist services, a restricted range of curriculum options and a high proportion of young inexperienced teachers (Commonwealth Schools Commission, 1975).

Moreover, the Philippine Constitution emphasized the importance of education. Section 1 of Article XIV of the 1987 Philippine Constitution states that the state shall protect and promote the right of all citizens to quality education at all levels, and shall take appropriate steps to make such education accessible to all. However, according to UNESCO, less than $10 \%$ of children of primary school age (6-11 years old) in the Philippines are out of school. Basic education faces perennial problems like shortage of books, facilities and classrooms particularly in the public school system and it is even worse in isolated and far-flung areas. Conversely, few research articles have documented lives of teachers in Geographically Isolated and Disadvantaged Areas (GIDA). Documentaries from news agencies have illustrated teachers' ordeal to deliver their services to children. These are stories of an elementary teacher who walks 23 kilometers daily (Legaspi, 2012), or trekking into the mountains (Mallari, 2010), conducting classes anywhere available (Umil, 2015) and other challenges.

Further, school administrator is primarily concerned with the maximum development of his/her teachers into professionally efficient persons they are capable of becoming because the teachers are important factors in the teaching-learning process. A competent and effective school administrator is one who affects others in the success of the organization, motivates them, and includes them in the process. The primary duty of a school administrator is to have their school reach its goals. Whether it is a primary or a secondary school, the school administrator is the most important person in a school's success (Yavuz, 2006).

But being an effective leader at this time of pandemic, especially navigating in the "new normal," is a different concept. It is about honesty, flexibility, plain and simple. It means being honest in day-to-day interactions, honest in the way one does business, and honest about the status of the organization. These are not easy times to navigate but being open and transparent with the team is crucial to long-term success. This issue is the main concern of the research that leads to the formulation of the study. The research focused on the changes and challenges experienced by school administrators, management and leadership styles in the new normal setting. From these concepts, the research investigated the challenges faced by the school administrators in isolated schools especially in this new normal setting. This would benefit, prepare and equip teachers and future educators to determine what really happens in the field.

\section{Statement of the Problem}

The study aimed to investigate the changes, challenges, managerial skills, and leadership styles of school administrators in geographically challenged public schools in the Division of Capiz. Also, the data collected from this study were used in formulating a primer for supplementary material that could be useful in the implementation of their Learning Continuity Plan. Specifically, this study sought to answer the following questions:

1. What changes have been brought about by the new normal setting of education?

2. What challenges have been experienced by the school administrators in this new normal setting of education?

3. What managerial skills were optimized in implementing public school education in geographically challenged areas in the new normal setting?

4. What leadership styles were optimized in implementing public school education in geographically challenged areas in the new normal setting?

\section{Theoretical Framework}

This study was anchored on the Management Theory of Gatewood (1995) management is a set of activities designed to achieve an organization's objectives by using its resources efficiently and effectively in a changing environment. The administrative and technical capabilities of a manager are important in coordinating the organization's activities and uses its resources to determine not only how well the organization realizes its vision, mission and goals but also how he will be judged in terms of his efficiency and effectiveness.

This study was also based on Leadership Characteristics Theory of Derue (2011), successful leaders differ from other people and possess certain core personality characteristics that significantly contribute to their success. Likewise, the Contingency Theory, Fiedler (1964), managers make decisions based on the situation at hand rather than a "one-size-fits-all" method was considered a foothold of the study. A manager takes 
appropriate actions based on importance to the current situation. Managers may utilize a leadership approach that includes participation from workers. This theory falls on the domain: school leadership wherein the principal must always be a problem solver.

\section{Conceptual Framework}

The study utilized the Input-Process-Output (IPO) model. In the IPO diagram, it includes all of the materials and the information required in the process, the specific details of the process itself, and the descriptions of all products and by-products anchored on the process that took place (Schmutz, 2014). The framework focused on the processes used to determine and analyze the changes and challenges experienced by the school administrators in geographically challenged areas and the managerial skills and leadership styles utilized as coping strategies amidst new normal setting due to pandemic for SY 2020-2021.

INPUT

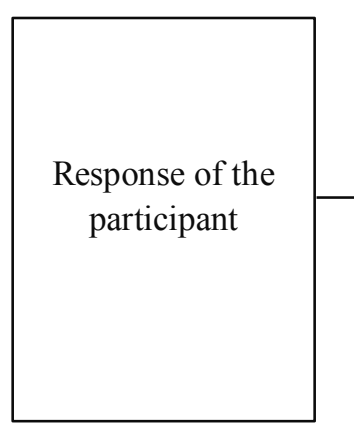

PROCESS

$\begin{aligned} & \text { In depth-unstructured open-ended } \\ & \text { interview }\end{aligned}$
Non-participant observation field notes
Reflexive diaries

\section{OUTPUT}

\begin{tabular}{|c|}
\hline \\
Primer for \\
Supplementary \\
material in \\
Learning \\
Continuity Plan \\
\hline
\end{tabular}

Figure 1: Schematic diagram of the research process

\section{Literature Review}

The pandemic has highlighted the big gap among schools in terms of equity, access and support for teachers, students and education, in general. Some schools quickly responded to the school closures because they had better access to digital technologies and more teachers who are trained and equipped with the skills needed in teaching with technology. Whether it is a big or small school, a private or public school, a city or rural school, no one was spared from the devastating effects caused by COVID-19 pandemic. Not only that, the challenge also lies on the hand of the parents as they play the role of teachers at home of their kids (Vegas, 2020).

Despite that, COVID-19 pandemic has resulted in at least one positive thing: a much greater appreciation for the importance of public schools. As parents struggle to work with their children at home due to school closures, public recognition of the essential caretaking role schools play in society has skyrocketed. Since parents and teachers play a fundamental role in supporting students to develop these crucial attitudes, particularly in the current situation, targeted policy interventions were designed with the aim of reducing the burden on parents and help teachers and schools make the most of digital learning.

As a response to the COVID-19 crisis, many countries around the world closed schools, colleges and universities to halt the spread of the virus. The sudden closure of schools meant that education policy makers, school principals and teachers had to find alternatives to face-to-face instruction in order to guarantee children's right to education.

In spite of being a desirable option compared to no schooling - which would have caused major interruptions in student learning with possible long-lasting consequences for the affected cohorts, the sudden switch to using digital instruction may have led to sub-optimal results if compared to a business as usual in-presence instruction, as teachers, students and schools all had to unexpectedly adjust to a novel situation (Burgess, 2020; This policy brief takes stock of some of the difficulties encountered by students, teachers and schools while adapting to online learning in order to understand how remote schooling can be improved further should online learning become necessary to prevent widespread transmission.

The first concern is that online learning is only available to children that have access to a broadband connection at home that is fast enough to support online learning. For example, in the United Kingdom, $71 \%$ of state school children received no or less than one daily online lesson (Green, 2020), while in 
Germany only $6 \%$ of students had online lessons on a daily basis and more than half had them less than once a week (Woessmann et al., 2020). Some economists have estimated that, as a consequence of this, students in the United States will resume their schooling in the fall of 2020 with roughly $70 \%$ of the learning gains relative to a typical school year on average and that the learning gains might be even smaller in mathematics, amounting to just 50\% (Kuhfeld \& Tarasawa, 2020). It is therefore important for education policy-makers to understand which factors have prevented certain children from receiving sufficient instruction - among them, in addition to the lack of infrastructure, the absence of adequate preparation in schools and among teachers, as well as, in some cases, the lack of curriculum guidelines. For example, in the United States, over one third of students have been completely excluded from online learning, particularly in schools with large shares of low-income students, while elite private schools experienced almost full attendance (Khazan, 2020). Similarly, evidence from England (United Kingdom) suggests that children from better-off families spent $30 \%$ more time on home learning than those from poorer families during the lockdown, and their parents reported feeling more able to support them than socio-economically disadvantaged parents, while students from richer schools had access to more individualized resources (such as online tutoring or chats with teachers) (IFS, 2020).

Further concerns relate to the fact that the effectiveness of online learning might have been hindered, in some cases, by the lack of basic digital skills among certain students and teachers, making them unprepared to adapt to the new situation so abruptly (OECD, 2020). For example, descriptive evidence based on PISA 2018 shows that there were major differences across countries and socio-economic groups in the use of technology for schoolwork before the pandemic among 15-year-olds, raising the concern that students who were less experienced might be those suffering the most from the shock caused by online learning. In addition, some teachers might also have struggled to adapt to online teaching so abruptly due to a lack of adequate digital skills, possibly contributing to a great heterogeneity in the quality of online teaching across schools. Yet, the report echoed earlier concerns about rural education: Geographic isolation still plagues progress toward equitable education and rural groups continue to be overlooked. In short, the report claims "education is at risk", and rural areas are susceptible. Geographic isolation of K-12 schools represents a unique challenge to schools with implications for school funding, staffing, resource acquisition, consolidation, transportation, and school choice among others. Rural schools face a constellation of contextspecific challenges and conditions (Provasnik et al., 2012), and while these issues in rural education are numerous and complex, the recurrence of the factors mentioned in the 2010 Education for All Global Monitoring Report (United Nations, 2010) suggest certain challenges are central and most pressing.

Resources for teacher salaries and staff development are frequently limited. It is not uncommon, for example, to find these schools without a professional library of teacher resources, or an instructional improvement program linked to school goals.For instance, the study conducted at the University of Maryland in Baltimore County, USA titled "Documenting Geographic Isolation of Schools and Examining the Implications for Education Policy" showed that geographic isolation of schools is relatively high within district particularly in rural areas. Although inclusion of schools in nearby districts greatly reduces isolation, many local markets of schools remain small. Results further show that geographic isolation varies greatly across states and across student demographics (Curran, 2019).

One survey in the United States about ethnic populations shows that the diversity in rural school becomes even more extreme. Rural, small schools have a greater tendency to be resource-bound as a group, rural schools tend to have a narrower tax base, and [are] highly susceptible to ups and downs within the local economy (García \& Weiss, 2017). Some rural parents, such as those in Australia, assume most of the educational responsibility.

To compensate for lack of expertise and human resources in rural schools, they also develop partnerships with community-based organizations and local universities and colleges (Stelmach, 2011). Because constraints such as geographic and professional isolation, small budgets, and staff turnover are common among many small, rural schools, they face a great challenge in implementing professional improvement opportunities and programs (Echazarra, 2019). Strategies used to overcome these constraints included networking, telecommunications, utilizing outside service agencies, conferences and workshops, restructuring school time, and providing incentives (Garcia, 2017). In a study entitled "Overcoming Professional Isolation in Small, Rural Schools", respondents identified staff renewal in rural schools as a significant issue requiring special attention.

Also, on the study entitled "Lonely Schools: The Relationship Between Geographic Isolation and Academic Attainment" which aims to identify whether all pupils and all disadvantaged pupils attending geographically isolated secondary schools have different academic attainment rates compared with their peers at less isolated schools, found that disadvantaged pupils attending more isolated schools had lower 
attainment rates (as measured by the percentage of students achieving grades of $\mathrm{C}$ or higher in English, Mathematics and at least three other subjects at General Certificate of Secondary Education [GCSE] level) than pupils in less isolated schools, when controlling for school demographics and prior attainment (Odell, 2017). It suggested that when framing the challenges of providing equitable opportunities in education, broader contexts beyond pupil characteristics, such as geographic isolation, should be taken into consideration.

In an article published at the University of Saskatchewan entitled "A Synthesis of International Rural Education Issues and Responses", different challenges were identified that rural schools might encountered: out-migration, gender inequity, poverty, declining student enrolment, staffing of teachers, remoteness, indigenous populations and curriculum relevancy which is generally classified to Macrosystemic Challenges, Mezosystemic Challenges and Microsystemic Challenges (Stelmach, 2011). Although these may seem like distal variables with respect to rural school challenges, they are persistent forces that rural educators must consider in their efforts to maintain and/or improve their schools.

Out-migration emphasize and promote that post-secondary education and professional careers, wellintentioned teachers perpetuate a hegemonic assumption that students who do not leave their rural lives are failures-educationally and socially.

\section{Research Methods}

This study was limited to the changes and challenges experienced by the geographically challenged schools administrators as well as their managerial skills and leadership styles optimized in the new normal setting due to COVID-19 pandemic. The respondents of this study were the school administrators situated in geographically challenged areas in the Division of Capiz for S.Y. 2020-2021.

The researcher utilized six (6) school administrators both in elementary and integrated public schools in mountainous and coastal areas in the Province of Capiz and were selected through purposive and availability sampling. The research instrument used was the in-depth unstructured open-ended questions. In analyzing the data gathered from the interview, the researcher utilized the qualitative data analysis procedure presented by Powell and Renner (2003).

\section{Results and Discussion}

Changes Experienced by the Respondents

Table 1 shows the results on the changes experienced by the school administrators in geographically challenged areas.

Table 1. Changes experienced by the respondents

\begin{tabular}{|c|c|c|c|c|}
\hline Key Question & $\begin{array}{l}\text { Theme responses to } \\
\text { the question were }\end{array}$ & Sub Themes & \multicolumn{2}{|c|}{$\begin{array}{l}\text { Recurrence } \\
\quad \mathrm{N}=6\end{array}$} \\
\hline \multirow[t]{4}{*}{$\begin{array}{l}\text { What are the } \\
\text { changes you have } \\
\text { experienced in the } \\
\text { new normal setting } \\
\text { of public school } \\
\text { education? }\end{array}$} & $\begin{array}{l}\text { Organizational } \\
\text { Management } \\
\text { Strategies }\end{array}$ & $\begin{array}{l}\text { Work Structure } \\
\text { Sending and receiving of } \\
\text { reports } \\
\text { Information Dissemination } \\
\text { Time Management }\end{array}$ & $\begin{array}{l}\text { KIIP-01, } \\
\text { KIIP-03, } \\
\text { KIIP-05, }\end{array}$ & $\begin{array}{l}\text { KIIP-02, } \\
\text { KIIP-04, } \\
\text { KIIP-06 }\end{array}$ \\
\hline & Personnel Monitoring & $\begin{array}{l}\text { Attendance } \\
\text { Performance }\end{array}$ & $\begin{array}{l}\text { KIIP-01, } \\
\text { KIIP-03, }\end{array}$ & $\begin{array}{l}\text { KIIP-02, } \\
\text { KIIP-05 }\end{array}$ \\
\hline & $\begin{array}{l}\text { Instructional Delivery } \\
\text { System }\end{array}$ & No face-to-face interaction & $\begin{array}{l}\text { KIIP-01, } \\
\text { KIIP-06 }\end{array}$ & KIIP-02, \\
\hline & $\begin{array}{l}\text { Health Management } \\
\text { Protocols }\end{array}$ & $\begin{array}{l}\text { Rules } \\
\text { Procedures }\end{array}$ & $\begin{array}{l}\text { KIIP-02, } \\
\text { KIIP-06 }\end{array}$ & KIIP-03, \\
\hline
\end{tabular}

Table 1 reflects the changes experienced by the respondents. Data revealed that changes experienced in managing an organization, individual work structures, sending and receiving of reports, information dissemination and time management.

Findings desclosed, the usual routines in school like the attendance, daily tasks and even the opening and 
closing of classes were affected because pandemic. The conduct of orientation for easy dissemination of information have few participants inspite holding the orientation by batches to cater the stakeholders. The findings were supported by respondents on scheduled group chat. This conforms with Section 5 of the IATF Resolution No. 88 series of 2020 which states mass gatherings but not limited to, movie screenings, concerts, sporting events, and other entertainment activities, religious services, and work conferences shall be allowed provided that participants shall be limited to fifty percent (50\%) of the seating or venue capacity. New normal setting led to a shift on how schools give instructional materials and on how they monitor students' performance. For distribution and retrieval of modules, parents to come to school and get the modules of their children, sometimes barangay officials distribute the modules. Module drop boxes were available at the barangay for ease of distribution.

Likewise, ICT coordinator sends the reports online but it is always followed-up by a hard copy to problem in the internet connection". Changes on the delivery of instruction or information was not limited to administrators and teachers. Different ways were adopted through text messaging and Facebook messenger and other ways like tarpaulins, Facebook and among stakeholders. The interview revealed, they experienced changes in terms of handling their time and schedule. New normal setting implies new way of handling work at the comfort of one's space and time even how teachers report to school and how administrators keep track of the attendance and the performance of their teachers have changed special arrangement were affected like report to school twice a week only but have to adopt "Work from Home."

As to section 5 of IATF Resolution No. 88 series of 2020 which states that participants shall be limited to fifty percent $(50 \%)$ of the seating or venue capacity, it was also among the confirmed changes. Seminars are one of the best ways to convey the message to a target audience in an effective way, but webinars were conducted for the purpose. Homeroom observations and monitoring were also different before the pandemic and in the new normal setting.

As to instructional delivery, learning delivery modalities that schools can adopt maybe a combination of the following, depending on the local health conditions, the availability of resources, and the particular context of the learners in the school or locality. It that included no-face-to face interaction (distance learning) wherein modular distance, online distance learning and Television/Radio-Based Instruction belongs to this. All the learning is done at home since there is no face-to-face interaction inserted modular print was utilized. It was used due to lack of gadgets and difficulty of conducting the online classes. Lessons were conducted through radio, television or cellular phones as what is applicable in the area where the learning process takes place. Changes in the contents of school curriculum, syllabi, lesson planning and scheduling of classes were also adjusted.

Observing safety and health protocols not only in school but as well as in other educational offices were directly followed to ensure the safety of everyone, new ways were implemented in this new normal setting of education. Including parents and other stakeholders conforms with Section 8 of IAFT Resolution No. 88 series of 2020 which states that all persons are mandated to wear full-coverage face shields together with face masks, earloop masks, indigenous, reusable, or do-it-yourself masks, or other facial protective equipment which can effectively lessen the transmission of COVID-19, whenever they go out of their residences, pursuant to existing guidelines issued by the national government subject to fair and humane penalties or punishments that may be imposed by LGUs or implemented by law enforcement agencies, respectively.

\section{Challenges Experienced by the Respondents}

Table 2 shows the results on the challenges experienced by the school administrators in geographically challenged areas.

Which challenges included social media connectivity, transportation, health and safety, parents' involvement and resources. However, most of the changes were acceptable but the concern on poor connectivity had affected majority of the respondents which should be given priority attention. Data on Table 2 also shows that respondents attested that one of the challenges they experienced was on transportation which further categorized to risk and fare adjustments. School administrators encounter risks in travelling from their homes to school on a daily basis. Respondents are of great disadvantage in terms of distance and type of terrain. The school is hard to reach especially during rainy seasons because of the slippery and muddy road which justified as school far flung in the district of Sapian. 
Table 2. Challenges experienced by the respondents

\begin{tabular}{|c|c|c|c|}
\hline Key Question & $\begin{array}{l}\text { Theme responses to the } \\
\text { question were sorted into: }\end{array}$ & Sub Themes & $\begin{array}{l}\text { Recurrence } \\
\qquad \mathrm{N}=6\end{array}$ \\
\hline \multirow{6}{*}{$\begin{array}{l}\text { What are the } \\
\text { challenges you } \\
\text { have experienced } \\
\text { in the new normal } \\
\text { setting of public } \\
\text { school education? }\end{array}$} & Connectivity & $\begin{array}{l}\text { Sending of reports } \\
\text { Attending of Webinar } \\
\text { Sending of Text Messages }\end{array}$ & $\begin{array}{l}\text { KIIP-01, KIIP-02, } \\
\text { KIIP-03, KIIP-04 } \\
\text { KIIP-05, KIIP-06 }\end{array}$ \\
\hline & Transportation & $\begin{array}{l}\text { Fare hike } \\
\text { Risk }\end{array}$ & $\begin{array}{l}\text { KIIP-01, KIIP-02, } \\
\text { KIIP-03, KIIP-04 } \\
\text { KIIP-05, KIIP-06 }\end{array}$ \\
\hline & Health and Safety & $\begin{array}{l}\text { Threats } \\
\text { Rules }\end{array}$ & $\begin{array}{l}\text { KIIP-01 KIIP-02, } \\
\text { KIIP-04 KIIP-06 }\end{array}$ \\
\hline & Parents Involvement & $\begin{array}{l}\text { Parents Attitude } \\
\text { Parents Literacy } \\
\text { Financial Difficulty }\end{array}$ & $\begin{array}{l}\text { KIIP-02, KIIP-03 } \\
\text { KIIP-04 KIIP-06 }\end{array}$ \\
\hline & Resources & $\begin{array}{l}\text { Material } \\
\text { Human }\end{array}$ & $\begin{array}{l}\text { KIIP-02, KIIP-03 } \\
\text { KIIP-04 KIIP-05 }\end{array}$ \\
\hline & Adjustments & $\begin{array}{l}\text { Use of technology } \\
\text { Multitasking }\end{array}$ & $\begin{array}{l}\text { KIIP-03 KIIP-04 } \\
\text { KIIP-05 KIIP-06 }\end{array}$ \\
\hline
\end{tabular}

This was seconded when respondent KIIP-03 stated that they "consume 30 minutes to 1 hour in travelling from the school to the main road". Travelling to their respective schools is harder when the weather condition is not good. As supplied by Barcena (2018) teaching in a remote school is a huge challenge. Teachers would encounter variety of uncomfortable means of transportation like "banka," "habal-habal," and even the use of animals such as horse or carabao just to reach the station. Teachers risk their lives and that of their entire family just to pursue their chosen vocation. These are stories of an elementary teacher who walks 23 kilometers daily (Legaspi, 2012), or trekking into the mountains (Mallari, 2010), conducting classes anywhere available (Umil, 2015) and other challenges.

Likewise, the condition of the road and the weather that the respondents have been struggling with but also the threats in their peace and security. Upland and mountainous areas in Capiz are known to be havens of New People Army (NPA), hence, unexpected circumstances could happen anytime. Among the stressful challenge was anxiety about a new disease and what could happen can be overwhelming and can trigger strong emotions in adults and children. Public health actions such as social distancing can make people feel isolated and lonely and can increase stress and anxiety. However, these actions are necessary to reduce the spread of COVID-19 (Centers for Disease Control and Prevention, 2020). School administrators were worried with their health so as parents and the community. It is a personal challenge that safety is through following the safety protocols.

On the other hand, parents are important stakeholders of the school. Because of their participation, many activities and projects are being implemented. It is also a fact that sometimes, they can be a source of conflict to administrators especially in the new normal setting. Hence, parents' involvement was identified as one of the challenges of the respondents. This was further classified to parents' attitude, parents' literacy and financial difficulty.

Physical location creates barriers for rural education. In many rural communities around the world, students must walk long distances or over tough terrain to reach their schools (United Nations, 2010). Geographically challenged areas are associated to households or families that are poor and far from each other. Parents are having a difficult time providing the needs of their families which in turn affects the educational system.

Findings related to Quejada and Orale (2018) which presents that geographically isolated communities are usually poor, households were very poor, parents have low educational background and some have not gone to school, students walk to the school for kilometers on daily basis and some of the teachers were teary-eyed sharing the stories of their students. Finally, respondents emphasized that one of the challenges they experienced in the new normal setting was adjusting to the changes implemented and its effects. Thus, the last theme identified concern with adjustment, both with school personnel and stakeholders. 
Respondents' Managerial Skills

Table 3 shows the results on the managerial skills described and optimized by the school administrators in geographically challenged areas in new normal setting.

Table 3. Respondents' managerial skills

\begin{tabular}{|c|c|c|c|}
\hline Key Question & $\begin{array}{l}\text { Theme responses to } \\
\text { the question were } \\
\text { sorted into: }\end{array}$ & Sub Themes & $\begin{array}{l}\text { Frequency/ Percentage } \\
\qquad \mathrm{N}=6\end{array}$ \\
\hline \multirow{7}{*}{$\begin{array}{l}\text { What managerial skills } \\
\text { were optimized in } \\
\text { implementing public } \\
\text { school education in } \\
\text { geographically } \\
\text { challenge areas in the } \\
\text { new normal setting? }\end{array}$} & Human Skill & Communication & KIIP-01, KIIP-02, \\
\hline & & Consideration & KIIP-03, KIIP-04, \\
\hline & & Motivation & KIIP-05, KIIP-06, \\
\hline & Conceptual Skill & Analytical & KIIP-01, KIIP-03, \\
\hline & & Decision Making & KIIP-04, KIIP-05 \\
\hline & & Maximizing Resources & \\
\hline & Technical Skill & Assistance & $\begin{array}{l}\text { KIIP-02, KIIP-03, } \\
\text { KIIP-04, KIIP-01 }\end{array}$ \\
\hline
\end{tabular}

Management skills enables a person to manage others effectively. While some skills vary based on industry, there are universal across every work in environment. In geographically challenged schools, three (3) managerial skills were identified: human, conceptual and technical. Human skills are the skills used to relate to one another. A person with strong human skills easily engages the audience, potential customer or current customer. The study subdivided the areas into communication, consideration and motivation.

As administrators, the primary goal is to inspire the teachers to bring out their best and help them become productive members of the community (Business Mirror, 2018). Administrators' good relationships with their teachers and by treating them with respect. A healthy relationship between the administrators, teachers and stakeholders is important to enable everybody to harmoniously work together, which will have a positive impact on the students.

The findings conform to Gordon and Wong (2000) when they mentioned that to compensate for lack of expertise and human resources in rural schools, administrators also develop partnerships with communitybased organizations and local universities and colleges. Likewise, this was similar to Wallace \& Boylan (2006) that in Australian communities, Aboriginal Cultural Centers provide cultural resources, host activities, and assist educators with planning culturally appropriate curriculum.

Results corroborated Stelmach (2011) compensate for lack of expertise and human resources in rural schools, they developed partnerships with community-based organizations and local universities and colleges. Another instance where respondent optimized the conceptual skill was when respondent KIIP-04 shared that "she took the chance when there was one photocopier offered a service to the school (but with pay). They utilized this to manage reproduction of modules. Later, they where able to cope with, added up of the printers and photocopiers they purchased." The respondent emphasized that somehow their problem was addressed.

Finally, data on Table 3 also shows that respondents described and optimized the technical skill in the new normal setting. As managers, one should possess the abilities and knowledge needed to perform specific tasks. They are practical, and often relate to mechanical, information technology, mathematical, or scientific tasks. It needs of delegating the tasks was emphasized to teachers. Aside from that, the work of a manager will be lessened, this was also a way of training the teachers to accomplish a task.

This is similar to what Ochavo (2004), the role of the manager varies accordingly; he is supposed to wear a hat that is best suited to a particular situation; his expertise to recognize roles and change roles readily is a mark of an effective manager. He plays a crucial role in attaining the goals of secondary education and he represents the school in different functions and he alone has direct access to the resources of the school. He can follow up educational innovations aimed at improving learning network with people and organization that can bring development to the school.

\section{Respondents' Leadership Styles}

Table 4 shows the results on the leadership styles described and optimized by the school administrators in geographically challenged areas in new normal setting. 
Table 4. Respondents' leadership styles

\begin{tabular}{|c|c|c|c|}
\hline Key Question & $\begin{array}{l}\text { Theme responses to } \\
\text { the question were } \\
\text { sorted into: }\end{array}$ & Sub Themes & $\begin{array}{c}\text { Recurrence } \\
\mathrm{N}=6\end{array}$ \\
\hline $\begin{array}{l}\text { What leadership styles } \\
\text { were optimized in } \\
\text { implementing public } \\
\text { school education in } \\
\text { geographically } \\
\text { challenge areas in the } \\
\text { new normal setting? }\end{array}$ & $\begin{array}{l}\text { Democratic } \\
\text { Affiliative } \\
\text { Combination }\end{array}$ & $\begin{array}{l}\text { Participative } \\
\text { Servant } \\
\text { Depends on } \\
\text { the situation }\end{array}$ & $\begin{array}{l}\text { KIIP-06, KIIP-04, } \\
\text { KIIP-03 } \\
\text { KIIP-02 } \\
\text { KIIP-01, KIIP-05 }\end{array}$ \\
\hline
\end{tabular}

A good leader can step into any given situation and construct a vision for a better future, brainstorm strategies for realizing that future, and execute a plan to see it to fruition. However, great leaders take steps to understand their strengths and weaknesses, and learning to practice the leadership styles that best suit them and their team, allowing them to accomplish more, compel greater change, and create a legacy that extends beyond their lifetime.

School administrators are leaders of their own school organization and as leaders, they have different ways of leading their organization. This depends greatly on the size, culture, members and location. As far as geographically challenged schools are concerned, three (3) styles of leadership were optimized by respondents and in most cases they have utilized. Thus, three (3) themes were identified: democratic, servant, and combination of other styles of leadership.

The data revealed administrators use optimized democratic style of leadership. It connected to Legario (2007) administrators use participative style of management where various ideas were given importance. While Ureta (2013), attested school administrators exhibit the participative leadership style in management. It was claimed school administrators consult teachers in programming school activities and involved teachers in preparing school programs and projects. Likewise Baňez (2010) participative leaders invite and encourage the team members to play an important role in the decision-making process; guides the employees on what to perform and how to perform, while the employees communicate to the leader their experience and suggestions if any to improve their tasks which conforms to the result of the study.

The second style of leadership identified was affiliative style of leadership sub-categorized to servant style. Servant leadership means using leadership skills to serve the greater good like find purpose and integrate it into everything even working to benefit the workplace, community, culture or the world at large (Robbins, 2019). Further, Rondael (2003) found that administrators used the contingent style of leadership and there was a significant correlation between leadership style and organizational effectiveness.

\section{Conclusions}

1. School administrators implemented and manage the organization, monitor the performance and attendance of personnel, delivery mode of instruction to students and observance of health procedures to meet the changes in the educational system brought about by the pandemic in the new normal setting of education.

2. The shift in the field of education to new normal setting is not easy to school administrators in geographically challenged areas to face additional challenges like poor internet connection, transportation hike, threat in health and safety of parents, teachers and learners, parents' involvement and adjustments of teachers to scarcity of school resources.

3. The need to focus for strong human relationship skills among parents and other stakeholders, analytic and decision-making skills, technical skills and abilities of school administrators in geographically challenged areas are important especially in the new normal setting.

4. There was variation on school administrators' leadership styles utilized in managing their organization for the new normal setting.

\section{Implications}

The new trends necessitate school administrators' flexibility and to fit in to the demands of the pandemic. Even in curriculum and planning development strategies and methods may range from simple to complex 
since the variations in the need and school setting of schools vary notwithstanding the resources of the school. Drawing a common line among these schools would be difficult if not impossible especially geographically challenged schools. An overlay of plans founded on school-based challenges would make a difference. In this regard of conduct surveys or case studies is appropriate in new normal setting of education. To capacitate teachers, it is tantamount for administrators to expose teachers to new technologies to at least at pace with other third world countries.

\section{References}

Echazarra Alfonso (2019). Learning in Rural Schools: Insights from Pisa, Talis and the Literature. OECD Education Working Paper No. 196

García, Emma \& Weiss, Elaine (2017). Education Inequalities At The School http://www.un.org/millennium/declaration/ares552e.htm isolation and academic attainment. The futures leaders trust, United Kingdom

Odell, Evan (2017). Lonely schools: the relationship between geographic OECD, (2020). Strengthening online learning when schools are closed.

Quejada, Aileen \& Orale, Ronald (2018). Lived Experiences of Elementary role of families and teachers in supporting students during the COVID-19 crisis starting gate Gaps, trends, and strategies to address them. Economic Policy Institute

Stelmach, Bonnie L. (2011). A Synthesis of International Rural Education Issues and Responses. University of Saskatchewan. pp. 32-42 support to countries in achieving the EFA Goals. Retrieved from http://portal.unesco.org/education/en/ev.phpURL_ID=47377\&URL_DO=DO_TOPIC\&URL SECTION=201.html Teachers in a Remote School in Samar, Phīippines. Samar State University 